level, for then very rapid pedalling would be necessary to maintain even a moderate speed. To obtain the advantage of high wheels or high gearing on the level and at the same time low wheels or low gearing on the hills, some highly ingenious devices are employed. On the table is a well-known one of these, the "Crypto-dynamic," which by a simple movement changes the relative speed of wheel and treadle Time will not permit me to describe the details of this arrangement, but it contains an epicyclic gear which is or is not in action according as the rider desires power or speed. There are several other devices having the same object, some depending on an epicyclic gear in a pulley, others on the use of two chains, only one of which is active at a time. These arrangements have the further advantage of enabling the rider to disconnect the treadles from the wheels whenever he pleases.

Tricycles on which two, three, or a whole family can go out for a ride together, involve few new principles, and I shall not for this reason have a word to say about them.

There remains one machine forming a class by itself, more distinct from all others than they are from one another. It is not a bicycle in the ordinary sense of the word; it is not a tricycle, for it has only two wheels. This machine is, from a scientific and therefore from your point of view, more to be admired than any other. It is called, after its inventor, the "Otto." The Otto bicycle and the Otto gas-engine will be lasting memorials to the ingenuity of the brothers who invented them.

No machine appears so simple, but is so difficult to understand as this. Tricyclists who have been in the habit of managing any machine at once, are surprised to find in this something which is utterly beyond them. They cannot sit upon it for an instant, for so soon as they are let alone it politely turns them off. When at length, after much coaxing, they can induce it to let them remain upon it, they find it goes the way they do not want. Riding the Otto, like any other accomplishment, must be learnt. Some seem at home on it in half an hour, others take a week or more. It is not surprising that that quick perception, in which ladies have so much the advantage of men, enables them to quickly overcome the apparently insurmountable difficulties which this machine presents to the beginner.

The rider when seated is above the axle of two large equal wheels; being then apparently in unstable equilibrium, he would of necessity fall forwards or backwards if some movement of recovery were not possible. The $C$ tto rider maintains his balance in the same way as the pedestrian. If he is too far forward, pressure on the front foot will push him back; if too backward in position, pressure on the rear foot will urge him forward. That this must be so is clear, for, whatever turning power be applies to the wheels, action and reaction being equal and opposite, they will produce an equal turning effect upon him. The steering of this machine is quite feculiar. In the ordinary way both wheels are driven by steel bands at the same speed; so long as this is the case, the Otto of necessity runs straight ahead. When the rider desires to turn, he loosens one of the bands, which causes the corresponding wheel to be free; if then he touches it with the brake or drives the other. wheel on, it will lag behind, and the machine will turn. It is even possible to make one wheel go forwards and one backwards at the same time, when the machine will spin like a top within a circle a yard in diameter.

There being no third wheel the whole weight is on the drivers, the whole weight is on the steerers; the frame, which is free to swing, compels the rider to take that position which is most advantageous, making him upright when climbing a hill, and comfortably seated when on the level. Owing to a curious oscillation of the frame which occurs in hill climbing, the dead points are eliminated, so the rider need not waste his strength at a position where labour is of no avail.

Though it has been impossible for me to do more than indicate in the most imperfect manner how numerous and beautiful are the principles and devices employed in the construction of cycles, I trust I have disappointed those who were shocked and horrified that so trivial a subject should be treated seriously in this Institution.

\section{DANGERS FROM FLIES}

$\mathrm{IN}$ a note communicated to the Gazzetta degli Ospitali for August I883, and republished in the current number of the Archives Italiennes de Biologie (tome iv. fasc. ii.), Dr. B. Grassi calls attention to the fact that fies are winged agents in the diffusion of infectious maladies, epidemics, and even parasitic diseases. During the summer season, when flies occur in swarms, it seems impossible to prevent them from settling on any and every object. In these countries, though sometimes troublesome, they are scarcely ever so numerous as in the warmer climates of the Continent, and even in these latter they are not often to be found such plagues as they are in Egypt; but in all these countries alike they may be seen to alight on all moist substances without distinction. It may be the expectorations of a phthisical or the ejecta of a tyrhoid patient that have last attracted these inquiring diptera ; but, irrespective of the material they may have been investigating, their next visit may be to the moist lips or eyes of a human being. Their feet, their mouth, and the pectoral portion of their bodies will have all come in contact with the infective mass, and will all in turn be more or less cleansed of it by the moisture of the freshly visited mucous membranes. But this danger has already been known and recognised, and it seems scarcely doubtful that in Egypt ophthalmia is constantly carried to the eyes of the infant natives by such winged visitors. Dr. Grassi calls our attention to even greater danger, and this from the ejecta of the flies themselves. Every housekeeper knows how the bright surface of a mirror or the gilt moulding of a picture-frame can be covered over with the little flecks left by these flies, no English words occur to us to translate therewith the phrase "les méfaits des mouches." The following experiences of Dr. Grassi relate to these:-At Rovellasca, between his laboratory, which is on a first floor, and his kitchen, which is on the ground floor, there lies a courtyard, with a distance between the windows of the two rooms of about ten metres. On a plate on the table of his laboratory he placed a large number of the eggs of a human parasite (Trichocephalus). After a few hours he found, on some white sheets of paper hanging in the kitchen, the well-known spots produced by the excreta of the flies, and on a microscopical examination of these spots, several eggs of the parasite were found in them. Some flies coming into the kitchen were now caught, and their intestinal tract was found quite filled with an enormous mass of facal matter, in which the presence of eggs of Trichocephali were detected. As it was practically impossible to keep all alimentary substances from contact with these flies, it follows that the chances of Dr. Grassi and his family being infected with Trichocephali were very great. As a matter of fact, the experiment was tried with non-segmented eggs of this worm. Another experiment was in the same direction. Dr. Grassi took the ripe segurents of a Tania solium (which had been in spirits of wine) and broke them up in water, so that a great number of the tapeworm's eggs remained susfended in the fluid. The flies came to the mixture, attracted by the sugar, and in about half an hour the ova of the tapeworms were to be found in their intestines and in the spots. Had these eggs been in a recent and living state, they would doubtless have been just as easily transported. To those who care to try these 
experiments, it is suggested that lycopod powder mixed with sugar and water is a good material, as the lycopod spores are easily detected.

It is self-evident that if the mouth-apparatus of the fly will admit of the introduction of such objects as have been above noted, that there will be no difficulty in its adnitting scores of the spores of many parasitic fungi, and above all of those belonging to the Schizomycetes, the possible cause of so much disease. Already has Dr. Grassi detected in fly excrement the spores of Oidium lactis, and the spores of a Botrytis, this latter taken from the bodies of silkworms dead of muscardine.

There arises, of course, the question of how far the active digestion in the intestines of the flies may not destroy the vitality of germs or spores thus taken in, but it would seem probable that in many instances the larger bodies swallowed may not serve as objects for assimilation, but may be got rid of as foreign bodies, and it will be borne in mind that the flies themselves fall victims to the growth of a parasitic fungus (Empusa musca, Cohn), which is probably taken first into their own stomachs.

Dr. Grassi promises to publish the results of his experiments in fuller detail. Judging of their interest by this abstract, they will well deserve to be followed up, and though in these countries our modern sanitary arrangements do not tend to the development of such immense swarms of flies as are so constantly to be met with in Italy, still the dangers to be apprehended from them there are possibly, though in a less degree, to be encountered here, and the investigation of the fact is easy to any one possessing a fairly average microscope and the power of catching a fly.

E. P. W.

\section{EDINBURGH MARINE STATION} $\mathrm{A}^{\mathrm{T}}$ the half-yearly meeting of the Scottish Meterrosubmitted a statement on the work done by the Fisheries Committee. This included preliminary reports from the Rev. A. M. Norman on the invertebrate fauna of the Scottish fresh-water lochs; Prof. Herdman's report of his researches connected with the fi heries of Loch Fyne, and similar reports from Messrs. Hoyle and Bed Aard from Peterhead and Eyemouth. After reading several interesting extracts from these reports, which will shortly appear in the Society's Journal, he then stated that the marine station at Granton would be formally opened for scientific work about the roth of next month by Prof. Haeckel of Jena. The floating laboratory, which has been named the $A r k$, was successfully launched on Saturday last, and it has accommodation for seven biologists. The steam yacht of thirty tons, which is to be called the Medusa, is to be launched on the $26 \mathrm{th}$ inst. at Glasgow, and will be at the station ten days thereafter.

The Station will then be possessed of the three most important requisites, viz. the floating laboratory, with abundance of sea water; a steam vessel fitted with all modern appliances for sounding, dredging, and other biological and physical investigations; and lastly, a most complete library in marine biology and physics. Mr. J. T. Cunningham, B.A. Oxon., Fellow of University College, Oxford, has been appointed Naturalist in charge of the Station; Mr. Hugh Robert Mill, B.Sc., who holds a Research Fellowship in the University of Edinburgh, is to carry on physical and meteorological investigations under the superintendence of Prof. Tait; Mr. Alexander Turbyne, fisherman, Keeper; Mr. William Bell, la:e Royal Navy, Engineer ; and it is hoped the arrangements will shortly be made that will enable a botanist and geologist to carry on systematic work at the Station. The captain of the yacht will be appointed next week.

British and foreign naturalists are invited to make use of the resources of the Station free of charge, and those who desire to do so are requested to communicate with
Mr. John Murray, Challenger Office, Edinburgh, stating the kind of work they propose to undertake and the length of time they will probably remain. Efforts are now being made to provide living accommodation for the naturalists and others who may be working at the Station. Immediately after the meeting Mr. Murray re ceived anonymously a donation of 1ool. towards the further equipment of the Station. We wish every success to this undertaking, and, from the liberal spirit shown in placing at the service of scientific men the unique facilities afforded by the Station for the prosecution of inquiries of the highest practical importance, we have every confidence that the public will not be slow in seeing that the funds required for its efficient maintenance are forthcoming.

\section{THE DEEP-SEA FISHES OF THE "TALISMAN"}

A MONG the many wonderful animal forms collected during the voyage of the Talisman none surpass the fishes in interest. In the exhibition, now open at the Jardin des Plantes, Paris, of the various specimens collected during this voyage, the collection of fishes holds a chief place. During the cruises of the Travailleur, owing to the apparatus employet, the capture of a fish was a rare event, but by the employment of a kind of drag-net on board the Talisman the number both of species and individuals taken was quite surprising. Once, on July 29 , in $16^{\circ} 52^{\prime} \mathrm{N}$. lat. and $27^{\circ} 50^{\prime} \mathrm{W}$. long, in one haul of the dragnet no less than I03 I fishes were taken from a depth of 450 metres. The chief surface fish noted in M. Filhol's very interesting papers, which are in course of publication in our French contemporary La Nature (to the editor of which journal we are in debted for the illustrations accompanying this notice), were the well-known shark (Charcharias glaucus), very common between the Senegal coast and the Cape de Verde Islands; its strange attendant fish, the so-callet pilot fish (Naucrates ductor), and the very curious and odd-looking fish of the Sargassum Sea, Antennarius marmoratus. It is noted that not only were the pilot fishes never molested by the shar'ss but that they constantly swam around them, sometimes even they were seen placing themselves against the shark's sides between their pectoral fins. Many observations were made on the strange Antennarius, the colour of whose body so closely approaches to that of the alga amidst which it lives that it enables these fish to approach almost unseen, and so quite easily take their prey. It is not, however, altogether unworthy of remark that this prey, consisting for the most part of small crustacea and mollusks, is also of the same general shade of colour as the mass of the weed, so that the assuming of this uniform dull tinge of colour must mean a heightened danger to some of these forms of life.

The great interest, however, of the fish captures of the Talisman centres in the remarkable forms taken from the depths of the sea, which were both considerable in the number of individuals and in the newness of the forms. The question of whether certain fish inhabit certain zones of depths was closely considered, and is answered in the affirmative. These zones are of very considerable depth, varying from 600 to over $36 ; 0$ metres, and in bringing up specimens from such areas of great pressure these suffer immensely through the phenomena caused by the rapid decompression of the air, the more remarkable effects being dilatation of the swim bladder, the eyes being squeezad out of their orbits, and the scales clothing the body are shed. In some cases even the fish $\mathbf{s}$ body has become smashed into pieces. Notwithstanding all these phenomena, the area in depth of the distribution of many of the deep-sea fish is very considerable. Thus Alepocephalus rostratus is met with between a depth of 868 and that of 3650 metres; Scopelus maderensis, between 